\title{
Spirocyclic Ketone Construction via Semipinacol-Type Rearrangement
}

\section{Representative natural products and pharmaceuticals with spiro[3.4]octane substructures:}

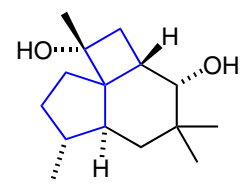

trefolane $\mathrm{A}$

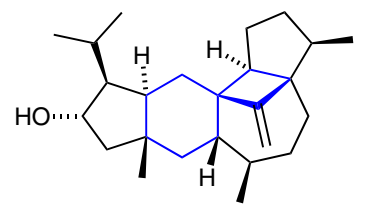

astellatol

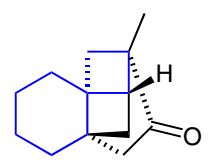

aplydactone

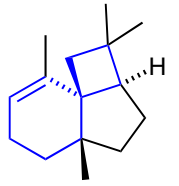

$\alpha$-panasinsene
Chemistry in

Medicine and Biology

\section{Key words}

semipinacol-type rearrangements

spirocycles

synthetic building blocks

General preparation of bicyclo[1.1.0]butanes followed by semipinacol-type rearrangement:<smiles>COc1ccc(S(=O)(=O)Cl)cc1</smiles>

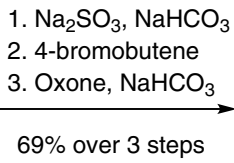<smiles>COc1ccc(S(=O)(=O)CCC2CC2)cc1</smiles>
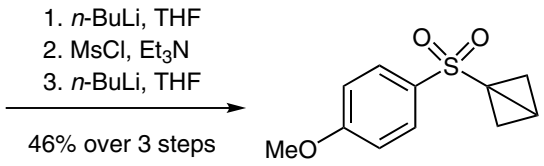

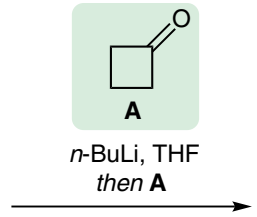

$80 \%$ yield
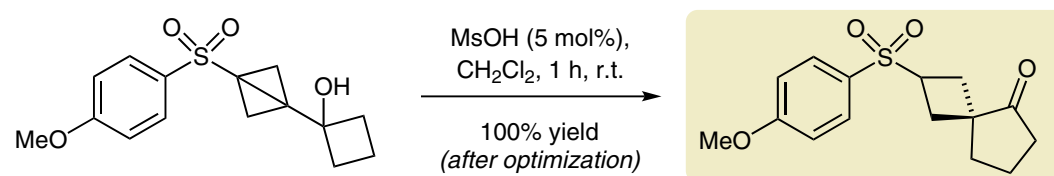

Proposed mechanism for the semipinacol rearrangement of bicyclo[1.1.0]butane:

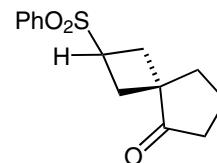

antarafacia

$\left(a_{1}\right)$
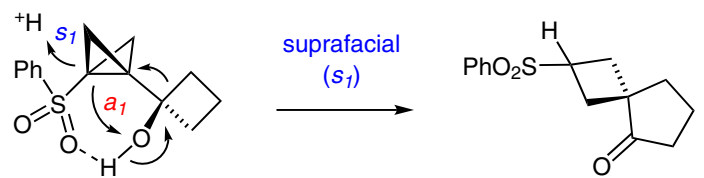

Significance: Spirocyclic motifs are often encountered in complex natural products and pharmaceutical compounds. This novel method exploits an acid- or halogen-catalyzed semipinacol rearrangement of (bicyclo[1.1.0]butan-1-yl)alkanols to access spiro[3.4] octanes and related heteroatomcontaining spirocycles chemoselectively and in good yield. Synthetic manipulation of the arylsulfone and carbonyl site could give access to an even greater variety of synthetic building blocks.
Comment: The sulfonylbicyclo[1.1.0]butanes used in these transformations are accessed easily and in moderate yield from aryl sulfonyl chlorides. Screening of acidic conditions identified methanesulfonic acid/dichloromethane as the most effective for the semipinacol rearrangement transformation. Although no natural products or pharmaceuticals were prepared, this methodology could be used to readily access complex structures, as shown above. 